\title{
Effect of lecithin on disability and plasma free-choline levels in Friedreich's ataxia
}

\author{
SUSAN CHAMBERLAIN, NORMAN ROBINSON, JANET WALKER, \\ CHRISTINE SMITH, SARAH BENTON, CHRISTOPHER KENNARD, \\ MICHAEL SWASH, BUNNY KILKENNY, AND SUSAN BRADBURY
}

\begin{abstract}
From the Friedreich's Ataxia Research Unit, Department of Pharmacology and Therapeutics, The London Hospital Medical College Department of Neurology, and the Department of Speech Therapy, The London Hospital, London
\end{abstract}

SUMMARY Four patients with Friedreich's ataxia took part in an open trial, in which they consumed $50-100 \mathrm{~g} /$ day lecithin granules (containing approximately $22 \%$ phosphatidycholine) for 16 weeks, but no improvement resulted. Several unwanted effects including diarrhoea, nausea, depression, "hot flushes" and weakness were experienced. Resting levels of free-choline in plasma were within the range found in 19 normal subjects. Sixteen other patients with Friedreich's ataxia also had normal free-choline levels. Treatment with lecithin significantly increased plasma free-choline levels, but there was a trend for these to fall towards baseline levels, despite continued ingestion of lecithin.

Because a defect in the pyruvate dehydrogenase complex has been reported in Friedreich's ataxia, ${ }^{12}$ and inhibition of this enzyme results in decreased synthesis of acetylcholine (ACh), ${ }^{3}$ it has been suggested that the neurological deficit in Friedreich's ataxia may be due to impaired central cholinergic mechanisms. Choline, the precursor of $\mathrm{ACh}$, has been reported to raise brain ACh levels in animals, ${ }^{4}$ leading to postsynaptic effects consistent with an increased release of this transmitter. ${ }^{5}$ Treatment with lecithin, a dietary source of choline may therefore, facilitate cholinergic transmission and some improvement has been reported in brief studies of patients with Friedreich's ataxia. ${ }^{67}$

\section{Patients and methods}

Two women aged 29 and 18 years (Cases 3 and 4), and a man aged 29 (Case 1) with classical Friedreich's ataxia 8 beginning between ages 7 and 14 years, and a man aged 56 (Case 2) whose disease was atypical in that it began in the third decade and progressed slowly, took part in the trial.

Address for reprint requests: Dr Christine Smith, Department of Pharmacology and Therapeutics, The London Hospital Medical College, London E1 2AD.

Accepted 15 May 1980
These four patients were asked to take lecithin granules $50 \mathrm{~g}$ daily with meals for eight weeks and then $100 \mathrm{~g}$ daily for a further eight weeks, in an open study which lasted for 20 weeks. In an initial screening session the test procedures were demonstrated and an ECG was performed in order to exclude patients with marked atrio-ventricular conduction abnormalities. The ECG was repeated at intervals during the trial.

Clinical assessment Patients were assessed on the day before starting treatment, then every four weeks during the four months they were taking the lecithin and finally four weeks after stopping treatment. Each assessment consisted of a battery of tests including clinical examination and assessment of the patient's ability to stand from the sitting position, to walk to and fro across the room and sit down again, and to perform tests of finger-nose co-ordination (eyes closed, eyes open) rapid hand patting, and holding the arms outstretched. All these activities were filmed. In addition, a standard task of placing pegs in a pegboard was timed. Speech was assessed using tests of rapid alternating movements of the tongue and jaw, and of repetitively uttered sounds. Tape-recordings of reading aloud and of the patients' descriptions of a picture, and their answers to standard questions were also assessed. On each day of the trial the patients graded their ability in walking and their hand co-ordination, using visual analogue scales. After the trial the six filmed sequences from 
each patient were randomised and each sequence from each patient was scored by five neurologists, using a scale of five points: normal, mild, moderate, severe and incapacitating disability (Grade 1-5).

Biochemical studies Routine haematological and blood glucose, cholesterol, triglycerides and liver profile tests were carried out at every assessment. The plasma fatty acids were measured, as a test of compliance; because of the high concentration of linoleic acid in the lecithin granules $(62 \%$ of the total fatty acids) the ratio of linoleic to oleic might be expected to increase if the patients were taking the treatment. Blood was taken from the four patients in the trial for estimation of free-choline plasma levels at 0,1 , or $2,4,8,12,16$ and 20 weeks. In 20 patients with Friedreich's ataxia, including those participating in the trial, and in 19 controls, baseline plasma free-choline levels were measured after isolation of free-choline by ultracentrifugation. ${ }^{10}$

\section{Results}

Only one of the four patients (Case 1) was able to complete the trial as planned. A second (Case 2) increased the dose from 50 to $75 \mathrm{~g} /$ day during the second eight-week period but a higher dose was found to cause nausea and weakness. The two women (Cases 3 and 4) found that increasing the dose beyond $50 \mathrm{~g}$ caused unacceptable diarrhoea and they took $50 \mathrm{~g}$ of lecithin throughout the trial. One of these patients (Case 4 ) became depressed and gained $6 \mathrm{~kg}$ weight whilst on the drug and stopped it after 11 weeks (see accompanying figure). All the patients noticed intermittent diarrhoea and two (Cases 2 and 3) felt flushed after taking their daily lecithin dose.

Clinical assessment The results of the six filmed assessments and pegboard tests are shown in the table. For every session, the sums of the scores for the filmed individual tests made by each neurologist were calculated and the means of these five totals are shown in the table. None of the patients reported improvement in their ability to walk or in hand co-ordination. Performance on the pegboard test generally deterio-

Table Assessment of performance before and during treatment with lecithin

\begin{tabular}{|c|c|c|c|c|c|c|c|c|}
\hline \multirow[t]{3}{*}{ Week } & \multicolumn{4}{|c|}{$\begin{array}{l}\text { Average total score for } \\
\text { flmed assessment }\end{array}$} & \multicolumn{4}{|c|}{$\begin{array}{l}\text { Time taken to transfer } \\
\text { pegs }(\text { seconds) }\end{array}$} \\
\hline & \multicolumn{4}{|l|}{ Case } & \multicolumn{4}{|l|}{ Case } \\
\hline & $\overline{1}$ & 2 & 3 & 4 & $I$ & 2 & 3 & 4 \\
\hline 0 & $12 \cdot 6$ & $12 \cdot 2$ & $9 \cdot 2$ & $15 \cdot 0$ & 220 & 315 & 114 & 254 \\
\hline 4 & $13 \cdot 6$ & $13 \cdot 8$ & $9 \cdot 4$ & $14 \cdot 4$ & 264 & 350 & 129 & 218 \\
\hline 8 & - & $12 \cdot 4$ & $8 \cdot 4$ & $13 \cdot 2$ & 310 & 310 & 112 & 315 \\
\hline 12 & $11 \cdot 2$ & $12 \cdot 6$ & $8 \cdot 2$ & $13 \cdot 8^{*}$ & 300 & 330 & 125 & $326^{*}$ \\
\hline 16 & $13 \cdot 0$ & $13 \cdot 2$ & $8 \cdot 2$ & $15 \cdot 4$ & 231 & 313 & 125 & 284 \\
\hline 20 & $12 \cdot 6$ & $13 \cdot 2$ & $8 \cdot 0$ & - & 226 & 284 & 140 & - \\
\hline
\end{tabular}

* Week 11 rated during the lecithin treatment but tended to return to the pretreatment score after lecithin was stopped. Similarly, the speech quality deteriorated during the trial and there was decreased ability to carry out rapid tongue movements. The ECG did not change during the trial.

Biochemical studies The pretreatment plasma levels of free-choline in the four patients ranged from 9.0 to $14.0 \mathrm{nM} / \mathrm{ml}$ (see figure). These were within the normal range (mean $11 \cdot 2 \pm$ s.e. $0 \cdot 7$ ) estimated in the 19 normal subjects. Sixteen other patients with Friedreich's ataxia also had levels within this normal range. The mean baseline value for free-choline in these 16 patients and in the four patients in the lecithin trial was $12 \cdot 7 \pm$ s.e. $0 \cdot 6$.

In all four patients plasma free-choline levels rose steeply in response to the $50 \mathrm{~g}$ dose of lecithin. Plasma levels in three patients at four weeks were $32 \cdot 0,34 \cdot 0$, and $42 \cdot 0 \mathrm{nM} / \mathrm{ml}$. However, in the other patient (Case 3) although a plasma level of $37.0 \mathrm{nM} / \mathrm{ml}$ was achieved after one week of treatment, the levels after one month's treatment was only $12.5 \mathrm{nM} / \mathrm{ml}$. This coincided with a period of vomiting and diarrhoea and may thus have been due to malabsorption of the lecithin.

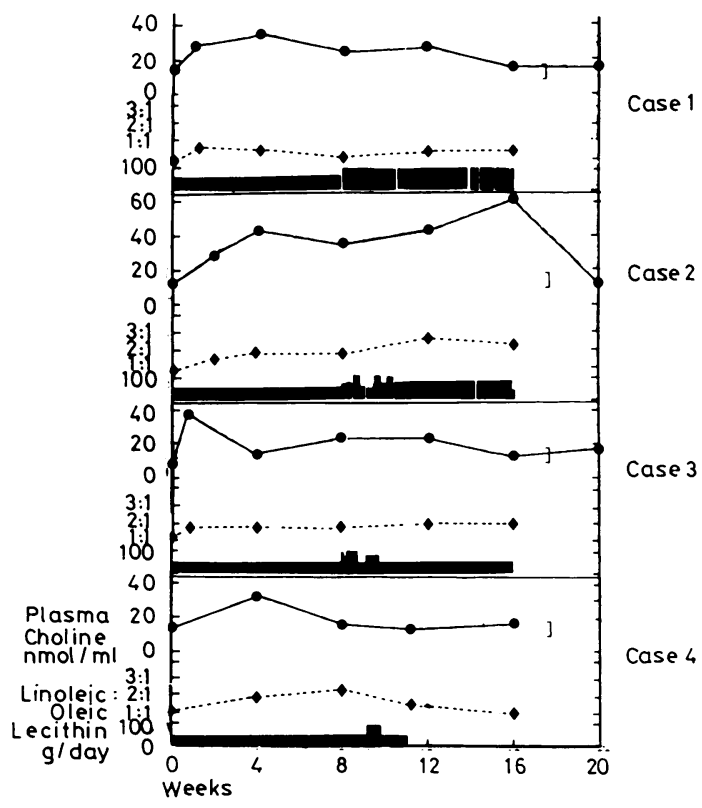

Figure Plasma free-choline levels - and linoleic-oleic acid ratios $\downarrow$ before and during lecithin treatment. ] indicates normal range of plasma free-choline levels $8 \cdot 0-17 \cdot 5 \mathrm{nM} / \mathrm{ml}$, in the group of 20 patients with Friedreich's ataxia. 
In the patient who increased the dose to $75 \mathrm{~g}$ / day (Case 2), the plasma level of choline reached $62.5 \mathrm{nM} / \mathrm{ml}$ after two months on this higher dose. This did not occur in the patient who took $100 \mathrm{~g}$ of lecithin (Case 1). In this case the plasma levels fell towards baseline, and faulty compliance probably contributed to this (see figure).

Plasma free-choline levels also dropped towards the baseline value in the two women who remained on the $50 \mathrm{~g}$ dose. Both these patients claimed they took the lecithin throughout the trial and their raised linoleic/oleic acid ratios (see figure) seemed consistent with this.

\section{Discussion}

There was no obvious improvement in the filmed tests and the patients noted no subjective improvement. Indeed the pegboard test results indicate that lecithin may have led to a deterioration in the patients' performance. Moreover, unwanted effects of lecithin were troublesome. Some of these for example depression, diarrhoea, nausea and weight gain, have been observed in other studies. ${ }^{71}$ The lecithin used in our trial had a calorific value of approximately 850 calories per $100 \mathrm{~g}$ and in view of the immobility of these patients, weight gain was not unexpected.

The finding of normal plasma free-choline levels in our 20 patients with Friedreich's ataxia suggest that there is an adequate supply of choline available for ACh synthesis in this disease. During the trial the plasma free-choline levels rose, indicating that the patients were taking their lecithin. However, the two patients who stayed on the $50 \mathrm{~g}$ dose throughout the trial showed declining levels of free-choline during the latter part of the study. Etienne et al, reported a similar trend in a group of patients with Alzheimer's disease who took lecithin for seven weeks. ${ }^{12}$ These observations may have implications for long term treatment with lecithin in the ataxias, Alzheimer's disease and in tardive dyskinesia, as trials of lecithin in these conditions have all been of short duration. ${ }^{12}{ }^{13}$

Absence of improvement in our patients does not necessarily imply that cholinergic drugs might not be useful in Friedreich's ataxia since lecithin may not be an effective cholinergic agent. ${ }^{14}$

In a controlled study some improvement of disability followed treatment with the anticholinesterase drug physostigmine. ${ }^{15}$ Further studies of cholinergic drugs should be undertaken to investigate the nature of this pharmacological effect.
We are very grateful to GR Lane, Health Products Limited for supplying the lecithin used in the trial. The Friedreich's Ataxia Group also supported the project.

\section{References}

1 Kark RAP, Rodriguez-Budelli M. Blass JP. Evidence for a primary defect of lipoamide dehydrogenase in Friedreich's ataxia. In: Kark RAP, Rosenberg RN, Schut LJ, eds. Advances in Neurology 21. New York: Raven Press, 1978: 163-80.

2 Barbeau A, Melançon S, Butterworth RI et al. Pyruvlate dehydrogenase complex in Friedreich's ataxia. In: Kark RAP, Rosenberg RN, Schut LJ, eds. Advances in Neurology 21. New York: Raven Press, 1978: 203-17.

3 Gibson GE, Jope R, Blass JP. Decreased synthesis of acetylcholine accompanying impaired oxidation of pyruvic acid in rat brain minces. Biochem J 1975; 148:13-23.

4 Hirsch MJ, Growdon J, Wurtman RJ. Increase in hippocampal acetylcholine after choline administration. Brain Res 1977; 125:383-5.

5 Ulus I, Wurtman RJ. Choline administration: activation of tyrosine hydroxylase in dopaminergic neurons of rat brain. Science 1976; 194: 1060- 1 .

6 Barbeau A. Lecithin in neurologic disorders. $N$ Engl J Med 1978; 299:200.

7 Livingstone IR, Mastaglia FL. Choline chloride in the treatment of ataxia. $\mathrm{Br}$ Med J 1979; ii: 939.

8 Geoffroy G, Barbeau A, Breton G et al. Clinical description and roentologic evaluation of patients with Friedreich's ataxia. Can J Neur Sci 1976; 3:279-86.

9 Wang PFL, Haubrich DR. A specific assay for free choline in plasma. Anal Biochem 1975; 63: 195-201.

10 Eckernas AS, Aquilonius SM. Free choline in human plasma analysed by simple radioenzymatic procedure: age distribution and effect of a meal. Scand J Clin Lab Invest 1977; 37: 183-7.

11 Smith CM, Swash M, Exton-Smith AN et al. Choline therapy in Alzheimer's disease. Lancet 1978; 2:318.

12 Etienne P, Gauthier S, Johnson G et al. Clinical effects of choline in Alzheimer's disease. Lancet 1978; 1:508-9.

13 Growdon JH, Gelenberg AJ, Doller J, Hirsch MJ, Wurtman RJ. Lecithin can suppress tardive dyskinesia. N Engl J Med 1978; 298:1029-30.

14 Hanin I. Choline and lecithin in the treatment of neurologic disorders. N Engl J Med 1979; 300:1113.

15 Kark RAP, Blass JP, Spence MA. Physostigmine in familial ataxias. Neurology 1977; 27:70-2. 